\title{
Research on Problems of College English Intercultural Teaching
}

\author{
Fanjiao Mao \\ Changsha Medical University, Changsha, Hunan, 410219
}

Keywords: English intercultural teaching; College English; problems and countermeasures

\begin{abstract}
With China's access to the World Trade Organization, more and more international exchanges are conducive to enhancing China's overall national strength, which will play an important role in promoting China's economic integration and diversified development. In modernization construction, English has become the universal language of the world to facilitate frequent exchanges between countries and promote the long-term development of the world economy. In College English teaching, improving the quality of English teaching and promoting the comprehensive development of the overall quality of college students has become the focus of current teaching. Therefore, this paper analyzes the problems existing in cross-cultural teaching of College English and puts forward the countermeasures to strengthen cross-cultural teaching of College English.
\end{abstract}

\section{Introduction}

With the continuous advancement of China's education reform, the cross-cultural teaching of college English is in line with the needs of social development and has become the future direction of English teaching, which is conducive to improving the level of college English education in China. In the modernization process, the implementation of the college English cross-cultural teaching model can continuously improve the quality of college English teaching and continuously promote the cultural exchanges between China and the West. It has important practical significance for cultivating high-quality talents with intercultural communicative competence.

\section{Existing Problems in College English Intercultural Teaching}

With the continuous development of college English teaching in recent years, the cross-cultural teaching of college English has also made considerable progress. However, it is deeply influenced by the traditional teaching model, and still exposes many problems in the process of teaching:

In September 2007, the Ministry of Education had already issued the "Course Requirements for College English Teaching." According to the provisions in the document, college English teaching is divided into three levels: general requirements, higher requirements, and higher requirements. These three levels only made clear requirements for the five skills of college English teaching, listening, speaking, reading, writing, and translation. However, this "requirement" does not make explicit provisions for cross-cultural teaching, and thus gives The cross-cultural teaching of English has caused certain difficulties. The instructional requirements for cross-cultural teaching in the above teaching requirements are not comprehensive and lack of pertinence. As a direct result, there is no detailed policy in the actual operation of college English as a guide, and teachers can only rely on the teacher's own exploration and exploration. Due to different teachers there is a huge difference. In view of this, students of the same university, English majors and non-English majors have shown great differences in the effectiveness of cross-cultural English learning. This difference is also evident between the same levels of different schools.

Under the current education system, teaching is mainly based on teaching materials. The proportion of cultural content in teaching materials will inevitably affect cross-cultural teaching. At present, there are few organic combinations of cultural content and language content in college English textbooks. Most of the textbooks focus on cultivating language ability, while the organization and arrangement of cultural teaching content is not systematic, and the proportion of 
articles that are descriptive or technically strong in the textbooks Larger, cultural materials involving spiritual aspects such as values, modes of thinking, and ethics are less. The lack of adequate and satisfactory cultural teaching materials is one of the outstanding issues in the cross-cultural teaching of college English in China. Teaching materials are the main basis and guidance for teachers' teaching and student learning, and they are also relying on Chinese students. Solving the problems existing in existing teaching materials is the key to achieving cross-cultural teaching of college English.

In college English intercultural teaching, the teacher factor is the key to whether cultural teaching can be put into place. First of all, teachers' cultural training and cultural experience are seriously deficient and cultural awareness is weak. As a result, teachers' cultural knowledge is in short supply and their cultural knowledge is not systematic. Secondly, the teachers themselves are the products of traditional English teaching. The teaching methods and ideas accepted by the students who only pay attention to the language form are reflected in their teaching. This is a concrete manifestation of the misunderstanding of teaching philosophy. For many years, when it comes to college English teaching, people naturally think of the teaching of pronunciation, vocabulary, grammar, and other knowledge. When it comes to the need for improved student abilities in college English teaching, they naturally think of "listening, speaking, reading, writing, The translation and training of these five basic skills, the imparting of cultural knowledge, and the cultivation of cultural abilities are in a secondary and inferior position.

In the current context, university students' English proficiency test assessment still relies on the National College English Test Band 46. In order to obtain a certificate through examinations, students usually perform English learning according to the requirements of the test content, and the students have the content and skills of the examination. The degree of emphasis and mastery has been much higher than the understanding of the English culture. In the classroom teaching of college English, the teaching content of teachers is also influenced by the assessment methods. The emphasis is on teaching language knowledge to help students cope with examinations. Therefore, cross-cultural knowledge is seldom involved. This kind of test system with 4-6 examinations as the main method not only profoundly affects students' learning methods and learning objectives, but also has a huge impact on teachers' teaching contents and models, resulting in unsatisfactory results in cross-cultural teaching of college English.

\section{Strategies for Strengthening Cross-cultural Teaching in College English}

In the process of college English teaching, teachers must update their concepts, cross-cultural teaching throughout the English classroom teaching, pay attention to the differences between Chinese and Western cultures, expand the students' knowledge of English learning, and perfectly integrate language teaching and cultural teaching. Together, the purpose of cross-cultural teaching is clarified, students' awareness of cross-cultural learning is cultivated, and students' interest in learning English is gradually enhanced, and students' comprehensive ability in applied learning is continuously improved. When formulating college English teaching plans, teachers should focus on cultural teaching, use language knowledge to enhance the connotation of cross-cultural teaching, make the structure of cross-cultural teaching more complete, and promote the simultaneous improvement of university students' language learning ability and intercultural communicative competence. The cross-cultural teaching model is continuously promoted and applied in college English teaching.

In college English textbooks, the proportion of Chinese and Western cultures is seriously out of tune. In the syllabus, the contents of Chinese culture are very few. Therefore, to strengthen college English intercultural teaching, it is necessary to combine Western culture, increase the proportion of national culture, and update English textbooks. The composition of the structure thus improves the effectiveness of cross-cultural teaching. In the actual teaching process, according to the English learning situation of college students, the preparation of cross-cultural teaching materials can enhance the enthusiasm of college students in English learning, promote the communication and exchange between teachers and students, and make the cross-cultural teaching of college English 
thoroughly implemented. Due to the differences between Chinese and Western cultures, university teachers must carefully compare Chinese and Western cultures in the process of cross-cultural teaching. They should balance the teaching of language and culture and integrate them so as to continuously improve the quality of college English cross-cultural teaching and promote college students. Comprehensive quality capabilities have been fully enhanced. For example, in Chinese culture, "red" stands for celebration, but in English, "red" stands for danger, alarms, etc. Therefore, by focusing on the differences between Chinese and Western cultures, the most appropriate words can be used to promote cross-cultural communication. Chinese and Western cultures are effectively blended.

In college English intercultural teaching, teachers occupy an important position and play an important role in promoting cross-cultural communication. Therefore, modern college English teaching must pay attention to the cultivation of high-quality talents, keep pace with the times, and establish new teaching concepts. To strengthen the awareness of cross-cultural teaching, improve the teaching power of teachers, and provide reliable guarantee for the effective implementation of cross-cultural teaching of college English. Major colleges and universities should strengthen the training of English teachers, carry out professional training for cross-cultural teaching, infiltrate cross-cultural teaching in all corners of the school, and promote the continuous improvement of teachers' teaching ability. With the rapid development of the modern economy, in practical teaching, students are better encouraged to participate in the study of Western culture, and the development of cross-cultural teaching of college English is being promoted towards diversification, intelligence, and modernization.

In various tests of college English, Western culture tests were strengthened to improve college students' English cultural performance, correct assessment of teaching effectiveness, and continuously improve the quality of college English intercultural teaching, and promote the continuous innovation of college English teaching reform in China. In the assessment of college English teaching, a sound assessment system is established, and cultural assessment is an important component to improve the students' familiarity with Chinese and Western cultures, thereby enhancing college students' English learning in terms of cultural knowledge, communication skills, and emotional communication. The interest is conducive to the detection of college students' English learning at any time and plays an important role in promoting the overall development of college students' comprehensive quality. For example, combining cross-cultural teaching tests and language tests, according to the different stages of English learning characteristics, develop a reasonable assessment criteria, so that cross-cultural teaching testing towards the normalization of development, in order to promote the effectiveness of college English cross-cultural teaching continues to increase.

While cultivating the cross-cultural learning awareness of college students, we must pay attention to the improvement of college students' intercultural communicative competence in order to truly achieve the purpose of college English teaching and promote the continuous improvement of college students' English communication practice. Therefore, according to the university student's learning environment, we should make full use of the school's online teaching resources, establish a practical platform for practice, and strengthen communication and exchange among students, so that undergraduates in frequent interactions, improve cross-cultural communication skills and promote the integration of Chinese and Western cultures. For example, in English, cross-cultural communication and learning activities are conducted on campus to innovate the forms of cross-cultural communication in English, improve the creativity of college students, and promote the continuous improvement of students' cross-cultural communication practice.

The theory of distributed cognitive theory holds that teachers are collaborators, leaders, participants in discussions, and dynamic coordinators. In college English learning, active and effective use of modern information technology has great advantages. Students mainly rely on self-directed learning and collaborative learning to form a "student-centered" learning model. This seems to be a teacher's role is not fully reflected, but actually belongs to teachers' The role has changed because students' individual English fundamentals, savvy, self-control, and learning styles 
are completely different and they are in great need of guidance from teachers. The leading roles of teachers are divided into "admire interest, guidance, inquiry, discussion, and communication". The relationship between teachers and students has changed from the original "authority-subordination" relationship to the "guidance-participation" relationship. In an information-based English learning environment, the factors that affect learning strategies are more complex. Due to the freedom and openness of the Internet environment, students are in urgent need of training and guidance in metacognition and cognitive strategies: learn to analyze what factors affect the learning process and results; learn to monitor, evaluate, and regulate their own learning behavior; in the learning process The Chinese will conduct self-diagnosis to understand their own weaknesses. In the actual teaching process, teachers can select appropriate training content and carry out targeted strategic guidance for students with different levels of English according to their interest and cognitive development level. Of course, the effectiveness of learning strategies depends on many factors, such as the nature of English learning tasks, individual differences in learners (gender, age, learning experience, learning style, etc.). Sometimes compensatory strategies and emotional strategies are needed to start. Compensation strategies can solve the problems faced by students when they are unable to obtain the necessary external support in an online learning environment. Emotional strategies can make up for the lack of a humanistic atmosphere and emotions that the students are experiencing.

\section{Conclusion}

According to the distributed cognitive theory, cognitive activities can be regarded as a series of dynamic activities such as media representation, transformation, and processing. Instead of learning English language knowledge from information technology, students use knowledge to construct knowledge. Network and multimedia are no longer teachers' means of imparting knowledge and knowledge, but are used as cognitive tools for students' active learning and exploration. Students, learning communities, and learning tools are equally important. The key lies in how to integrate them and form a synergistic understanding to better help students learn and improve English learning.

\section{References}

[1] Chen Lin. The importance and countermeasures of cross-cultural teaching in college English [J]. Tutoring World, 2012(14):74-75.

[2] He Shengzhong. College Cross-cultural English Teaching Structure Model and Practice Model[J]. Journal of Jiangxi Institute of Education, 2014(01):72-76.

[3] Li Zaoxia. Research on College English Cultural Experience Teaching[D]. Xi'an: Shaanxi Normal University, 2012.

[4] Li Nan. Research on the Two-way Import of English and Chinese Culture in College English Teaching from the Perspective of Cross-cultural Communication [D]. Changchun: Jilin University, 2012.

[5] Leong Lin. On the Problems and Countermeasures of English Intercultural Teaching [J]. Reading and Writing, 2010(12):33-34. 